\title{
Perceiving and desiring: a new look at the cognitive penetrability of experience
}

\author{
Dustin Stokes
}

Published online: 14 January 2011

(C) Springer Science+Business Media B.V. 2011

\begin{abstract}
This paper considers an orectic penetration hypothesis $(\mathrm{OPH})$ which says that desires and desire-like states may influence perceptual experience in a nonexternally mediated way. This hypothesis is clarified with a definition, which serves further to distinguish the interesting target phenomenon from trivial and non-genuine instances of desire-influenced perception. Orectic penetration is an interesting possible case of the cognitive penetrability of perceptual experience. The OPH is thus incompatible with the more common thesis that perception is cognitively impenetrable. It is of importance to issues in the philosophy of mind and cognitive science, epistemology, and general philosophy of science. The plausibility of orectic penetration can be motivated by some classic experimental studies, and some new experimental research inspired by those same studies. The general suggestion is that orectic penetration thus defined, and evidenced by the relevant studies, cannot be deflected by the standard strategies of the cognitive impenetrability theorist.
\end{abstract}

Keywords Cognitive penetrability - Theory-ladenness · Perception · Experience Cognition · Modularity

If folk psychological language is any guide, we sometimes perceive what we want to perceive. Parents tell their children things like 'You only hear me when you want to hear me.' Someone may tell her spouse, 'It was right there in front of you, you just didn't want to see it!' Such charges are common in everyday contexts and, presumably, are often just metaphorical. One should resist, however, the temptation to hastily conclude that these are just empty contemporary idioms. Linguistic trends

D. Stokes $(\bowtie)$

Department of Philosophy, University of Toronto, 170 St. George St.,

Toronto, ON M5R 2M8, Canada

e-mail: d.stokes@utoronto.ca 
such as these often have a way of tracking some real fact about the world. The fact that these idioms all suggest is that we sometimes perceive what we want to perceive. A question for the philosophy of mind and cognitive science is whether this is a fact: do our desires influence our perceptual experiences in some interesting way?

Current science of the mind may not afford a conclusive answer to this question, but it does provide important data. Some of this data, it will be argued below, counts against the negative answer favoured by many philosophers (implicitly or explicitly), namely, that higher level states like beliefs and desires do not affect experience. An opposing thesis, the orectic penetration hypothesis $(\mathrm{OPH})$, says that desire-like mental states sometimes causally influence perceptual experience by strictly internal mechanisms. This hypothesis is sharpened and clarified with a definition in Sect. 1. This analysis usefully distinguishes interesting instances of the phenomenon from trivial ones, and (as discussed in Sect. 3) precludes the application of the standard strategies taken by the sceptics of higher-level influence on perception.

Second, with this definition and hypothesis in hand, one can consider the philosophical and scientific importance of the possibility of orectic penetration. This possibility is of interest, most simply, since it contributes to a general account of mental architecture. Indeed, if desire or desire-like states do influence perception in some non-trivial way, then we have an interesting case of cognitive penetrationwhere a cognitive state causally influences perceptual experience. Cognitive penetrability is of interest to epistemologists, philosophers of mind, and cognitive scientists for a variety of reasons. A few of these issues are discussed in Sect. 2 below.

Finally, some experimental cases can be adduced to motivate the plausibility of the orectic penetration hypothesis. These cases must be defended against the more orthodox claim that perceptual experience is cognitively impenetrable. The latter theorists employ some standard strategies for deflecting any putative case of higher order influence on perception. Ironically, it turns out that one of the first experimental studies on the possibility of desire-influenced perception may best evade these strategies. This study and its general interpretive spirit, it will be suggested, deserves renewed consideration.

\section{The orectic penetration hypothesis}

In an obvious sense, perceptual experiences influence our desires and evaluations. Indeed, one sometimes needs to experience something before one can want it or evaluate it as good, bad, beautiful, etc. Until one tastes chocolate or coffee or Scotch whisky one does not crave such things. Can the causal arrow run the other direction? Might a desire or some other orectic mental state influence perceptual experience? Recent philosophy of mind and cognitive science has tended to answer this question in the negative. Desires do not influence experience, since more generally, higherlevel mental states do not directly or internally influence perceptual processing so as to affect experience. 
The alternative thesis is worth considering. Suppose I might hear something in a certain way, see something in a certain way, taste something a certain way, because of a desire of mine. Suppose, that is, that the character or content of an experience may be different as a result of some desire or wish or preference held by the perceiver. A familiar and intuitive example may help.

Consider cases of disagreement about what is seen in a sporting match. During a recent football season, the pubs in England were filled, as they often are, with fans for two rival clubs: Arsenal and Manchester United. At one point in the game, Arsenal's keeper was caught off the goal leaving Manchester United's striker in a good position to score. However, one of Arsenal's defence managed to place himself between the shot and the goal, effectively blocking the shot. Now, on first sight, it wasn't clear whether the Arsenal player used his head or his elbow to block the shot. If he used his head, then it is a good bit of defence. If he used his elbow, it is a hand ball and a free kick for Manchester United. Important stakes, and so obviously Arsenal fans would prefer the former, Manchester United fans, the latter. The trouble was that even upon replay, it wasn't clear which was the case. Unless, of course, you were a devoted fan: while the instant replays were shown, Arsenal fans reported that they "could see" the ball contact the defenseman's head. Manchester United fans reported the opposite: they "could see" the ball contact his elbow. Some of these reports are no doubt accompanied by a guilty conscience, but assume some of them are honest. ${ }^{1}$

These experiences are good candidates for desire-influenced perception: these fans were seeing what they wanted to see. Call any such case of perceptual experience orectically penetrated, which may be defined as follows.

(OP) A perceptual experience $E$ is orectically penetrated if and only if (1) E is causally dependent upon some orectic state D and (2) the causal link between E and $\mathrm{D}$ is internal.

An orectic penetration hypothesis $(\mathrm{OPH})$ says that perceptual experiences of the kind defined in OP may occur. Desire-like mental states sometimes causally influence perceptual experience in a non-externally mediated way.

Some clarifications are in order. First, to be clear, OPH is distinct from the wellestablished thesis that desires and desire-like states can affect rational decisionmaking, belief-formation, and other cognitive processing. It is also distinct from theses concerning self-deception (at least insofar as the deception involves a selfmotivated adjustment to one's beliefs or other doxastic states). OPH is a substantially more controversial thesis; it concerns desire-influenced perceptual experience.

The concepts 'perceptual experience' and 'orectic state' deserve brief clarification. Perceptual experiences are, minimally, states with phenomenal character and

\footnotetext{
${ }^{1}$ One can think of examples from whatever sport one prefers. Think of a controversial strike called in baseball. Think of a questionable case of the basketball leaving a player's hand before the buzzer. Think of controversial cases where the ball is close to the line in tennis (perhaps many of John McEnroe's tantrums were based on a perceptual experience relevantly distinct from the line judge's). All of these are candidate cases, circumstances where (even upon replay) the image is to some degree ambiguous and relevant desires may influence perceptual experience.
} 
ones that result (non-trivially) from one or more sensory organ. In Nagel's famous terms, there is something it is like, for the subject, to have a visual experience, an auditory experience, an olfactory experience, and so on (Nagel 1974). This assumption is neutral with respect to the relation between the content of perceptual experience and its phenomenology.

'Orectic state' is understood to denote desires and desire-like mental states. So in addition to desires, orectic states include likes, preferences, hopes, wishes, values, and longings, among others. For a start, orectic states are typified by a drive or motivation towards some object or outcome, where this drive disposes the agent to act, other things being equal, so as to satisfy the attitude or state in question (to acquire the object or the outcome of the orectic state). A desire for a beer is an attitude that disposes one to get a beer. My liking of rock and roll disposes me to purchase albums and attend concerts. Your hope to get the job disposes you to take extra time preparing the application. These are all orectic states. ${ }^{2}$

One additional clarification on the notion of desire. It is assumed here that some desires are cognitive states. This assumption is motivated by the following features of desire. Some desires are representational (for example, the desire for money); some desires have propositional content (for example, the desire that Jones win the election); and some desires play an ineliminable role in decision making and reasoning (for example, the desire to invest wisely). The same can be said for other orectic states such as goals, wishes, hopes, and values. Mental states that meet these characteristics are, at least broadly speaking, cognitive. One might think that this assumption is incompatible with a common philosophical practice of categorizing desires as 'conative' or 'affective', by contrast with other mental states like beliefs and memories. In fact, the assumption is consistent with this categorization. Conative states are motivational states; and affective states are typified by a phenomenal or emotional character. Granting the plausible claim that (at least some) desires are both conative and affective in these respects, this does not imply that all desires are non-cognitive (in the minimal sense of 'cognitive' characterized above). Generally, 'cognitive', 'conative', and 'affective' are terms for non-exclusive mental state categories. ${ }^{3}$

Clarifying the clauses of the definition clarifies the corresponding OPH. This will also serve to distinguish the target phenomenon and obviate possible confusions. Clause (1) of OP should be understood as follows. D is a non-sufficient cause of E. There are other relevant causal factors. As a first pass, one may interpret the causal dependency counterfactually. The suggestion is only that an orectic state is causally relevant such that, counterfactually, if state $\mathrm{D}$ had not been present in the perceptual-cognitive system of the agent, then that agent would not have had

\footnotetext{
2 Two brief notes. First, understanding orectic states in this way makes minimal commitments to a theory of desire or of, more broadly, orexis. A number of distinct and incompatible conceptions of desire are consistent with OP, e.g. Armstrong (1980), Smith (1994), Schroeder (2004) and Stalnaker (1984). Second, 'desire' will sometimes be used below as shorthand for any orectic state.

${ }^{3}$ It is worth noting that this way of thinking about desire comports with the thinking of potential opponents of $\mathrm{OPH}$-namely, cognitive impenetrability theorists, as discussed below-who include goals, values, and "other utilities" (i.e. other than belief) as possible penetrating cognitive states (i.e. those states that the same thinkers deny can influence perception, and thereby deny the cognitive penetration of, at least some of, perception). See Pylyshyn (1999, p. 343) and Fodor (1983, 1985).
} 
perceptual experience E. Note also that this way of defining orectic penetration allows for a desire to influence a belief or some other mental state, which then influences E. This scenario is perhaps not quite as striking but the (internal) causal dependency still obtains.

Clause (2) of OP should be understood as follows. Assume for simplicity that a mental process is just a series of (internal) mental events. Mental processes that stand in a direct causal relation with a perceptual experience can be thought of as unscreened or immediate causal ancestors. Clause (2) says that if one of these unscreened internal causes involves a desire-that is, the causal chain runs from experience back to a desire without deviating from the internal process- then the perception depends (internally) upon a desire. Counterfactually, had D not been present in the process, E would not be had by the subject. D is thus a necessary causal condition for E. Understood probabilistically, the desire is not a strictly necessary causal element, but one that is highly relevant to the probability of that perceptual experience. E is more likely to be had when D is present, and less when not present. The preferred notion of causation is of little matter so long as the internal causal dependency is maintained.

Finally, clause (2) of (OP) excludes trivial cases. For example, I may desire to see my dog rather than my computer screen. I satisfy my desire by shifting my visual gaze from what is directly in front of me to what is several degrees to my immediate right. You may desire to smell the sea and as a result spontaneously make your way to the nearest coast. In cases like these, a desire to have a perceptual experience motivates an action (or set of actions) which eventually results in the desired experience. The perceptual experience depends counterfactually upon the relevant desire. But this is not a relevantly interesting class of phenomena. Clause (2) insures that these are not instances of orectic penetration, since in each case the desire is screened from being internally, causally efficacious: the desire causes an (external) action which eventually results in the experience. ${ }^{4}$

Clause (2) also excludes deviant cases. Imagine cases where one desires to have a particular perceptual experience, and so takes a drug to elicit that experience, or hires a back alley neurosurgeon, or submits to some kind of Experience Machine. One would thus have the desired experience, and as a result of one's desire. But while D may be a causal ancestor of $\mathrm{E}$, the causal link is not purely internal and the desire is screened off. These are not cases of orectic penetration as defined.

\section{Philosophical and scientific relevance}

Before providing plausible experimental cases of orectic penetration, the philosophical and scientific relevance of the phenomenon should be clarified. What sorts

\footnotetext{
${ }^{4}$ For that matter, some of these cases may be effectively ruled out by clause (1), for example if the causal dependence is understood counterfactually. An olfactory experience of the sea may not depend counterfactually on a desire to smell the sea. You might drag me to the sea, and I would then experience the sea whether or not I had the corresponding desire. Clause (2) thus insures the exclusion of desiremotivated cases involving sophisticated ceteris paribus clauses-clauses to the effect that the context is such that the general causal dependence holds and (1) is satisfied.
} 
of implications would the truth of OPH have? Most simply, it would contribute to an overall architecture of the mind, and in turn provide an explanandum for the behavioural and brain sciences. If desires influence perceptual experience in the described ways, we will want to know why-e.g. evolutionarily-and how-e.g. neurophysiologically.

More specifically, if one grants that (some) desires are cognitive, then $\mathrm{OPH}$ is inconsistent with a cognitive impenetrability thesis. A cognitive impenetrability thesis says that for any two perceivers (or for the same perceiver at different times), if one holds fixed the object or event of perception, the perceptual conditions, the spatial attention of the subject, and the conditions of the sensory organ(s), then the perceptual experiences of those perceivers will be identical (see Macpherson, forthcoming). If the experiences of the two perceivers are distinct in these circumstances, and as a result of distinct cognitive states of the perceivers, then experience is, instead, cognitively penetrable. As one cognitive impenetrability theorist defines it, "[I]f a system is cognitively penetrable then the function it computes is sensitive, in a semantically coherent way, to the organism's goals and beliefs..." (Pylyshyn 1999, p. 343). ${ }^{5}$

OPH suggests that you and I may have distinct experiences-holding all the relevant perceptual conditions fixed-as a result of our distinct desires. An orectically penetrated experience involves a higher-order cognitive state (a desire, wish, like, etc.) influencing the content or character of a perceptual experience. Commitment to $\mathrm{OPH}$ therefore implies commitment to the cognitive penetrability of experience. ${ }^{6}$ Two motivations for maintaining the opposing cognitive impenetrability thesis - modularity and the theory-neutrality of observation-are considered below. OPH bears consequences for these issues as well.

Some theorists maintain that cognitive and sensory systems are modular in their operation. Visual, auditory, and haptic sensory systems, for example, perform discrete sets of computational tasks and are, in Jerry Fodor's terms, informationally encapsulated (Fodor 1983). A commitment to informational encapsulation of perceptual modules implies the cognitive impenetrability of those modules. So any modularity theorist who makes this commitment has independent motivation to resist cognitive penetration and, more specifically, orectic penetration. If perception can be penetrated by desires or other cognitive states, (some) modularity theorists will have to provide an alternative explanation of penetration without abandoning strong modularity of sensory systems. ${ }^{7}$

Orectic penetration and cognitive penetrability are also relevant to a traditional debate in philosophy of science concerning the relation between observation and

\footnotetext{
5 According to Fodor, processes are cognitively penetrated if they are "importantly affected by the subject's beliefs, his background information, or his utilities" (Fodor 1983, p. 73). Given what Fodor says elsewhere, desires seem to be included amongst the relevant cognitive states (e.g. see Fodor 1983, p. 68).

${ }^{6}$ Indeed, OP readily generalizes to a definition of cognitive penetrability by simple replacement of the desire placeholder ' $D$ ' with a general placeholder for cognitive states.

7 See Fodor (1983, 1985, 1988), Pylyshyn (1984) and Sperber (1996). See Stokes and Bergeron (MS) for a dilemma for modularity architectures, one horn of which challenges a commitment to informational encapsulation by appeal to the incompatibility with plausible cases of cognitive penetrability of perception.
} 
theory. Some theorists have maintained that observation is theory-neutral, others that observation is theory-laden. According to the first view, empirical observations are made in a way that is uninfluenced by theoretical background. If observations are made in a way that meets standards of scientific method, whatever those standards should be, then those observations provide objective data for theory construction, and may adjudicate, all else being equal, between competing theories. Others have argued that observation is theory-laden (Feyerabend 1962; Hanson 1958, 1969; Kuhn 1962). Theory-ladenness presents a challenge to both rational theory choice and the prospects for scientific knowledge. If observation is influenced by theoretical background, then observation does not provide objective data to support, test, or choose theories, but instead already imbeds theoretical interpretations. ${ }^{8}$

If perceptual experience is penetrated by theories or belief, and observation is based on perception (or just is perception), then observation is theory-laden. ${ }^{9}$ Friends of theory-ladenness thus stand to benefit from the truth of any thesis that maintains that beliefs or theories are among cognitively penetrating states. A cognitive impenetrability thesis does not entail that observation is theory-neutral (if observation is something over and above perception), but if true, this would eliminate one possible way in which observation is influenced by theory. So friends of theory-neutrality should be motivated to show that experience is not penetrated in these ways. And indeed, this is how the debate has largely played out between Paul Churchland and Jerry Fodor. Churchland maintains that observation is theory-laden, since perception is influenced by concepts, knowledge, learning, and theory (Churchland 1979, 1988, 1989). Fodor argues that perception is (sufficiently) cognitively impenetrable, and on this basis maintains that theory-neutral observation may provide a foundation for empirical knowledge (Fodor 1984, 1988). ${ }^{10}$

It should be obvious that in the context of scientific theory testing and choice, orectic penetration would be particularly problematic. Suppose one's desires regarding one's theories might influence one's perception. In turn, one might then appeal to one's observations (based on or identified with those perceptual experiences) to further motivate one's theoretical choices. This circularity would undermine the epistemic role of observation in this particular scientific investigation and, if sufficiently widespread, undermine that role entirely.

This last epistemic concern regarding observation generalizes. As Susanna Siegel has recently argued, cognitive penetration of experience would have significant consequences for the epistemic justification of perceptual states (Siegel, forthcoming). In some cases, the penetration would be an epistemic good. For example, a well-trained scientist or medical doctor may see things better, and make better

\footnotetext{
${ }^{8}$ For a recent survey on theory-laden observation and science, and how it engages with perception and cognitive penetration, see Brewer and Lambert (2001).

9 An unfortunate ambiguity in this literature is that some use 'observation' to refer to perception, others to something more like judgement or belief (about what one perceives).

10 See Macpherson for additional discussion of possible moves for both Churchland and Fodor (Macpherson, forthcoming). See Siegel for discussion of possible relevant cases of cognitive penetrability, including cases of desire-influenced perception in the context of scientific observation (Siegel, forthcoming).
} 
decisions on the basis of that experience, in virtue of her knowledge and expertise. However, if experience is to provide evidence for beliefs or, on some accounts, a foundation for knowledge, then there may be cases where penetration would be epistemically problematic. Siegel considers a case where Jill believes that Jack is angry. Suppose this belief influences Jill's visual experience of Jack such that Jack appears angry to Jill. If Jill takes her visual experience as evidence for her belief that Jack is angry, she has effectively moved in a circle, with her belief that Jack is angry supporting her belief that Jack is angry. On few accounts of epistemic justification is this acceptable. ${ }^{11}$

Orectic penetration would be epistemically problematic and perhaps without exception. Seeing something or seeing in a way because one wants would undermine the justificatory role that, many think, experience plays. To illustrate, consider an exaggerated example. Suppose you and I disagree about the colour of a friend's car. We place a bet: you bet that the car is brown and I bet that the car is red. Presumably, we each have a corresponding desire: you want the car to be brown and I want the car to be red. Should either of these desires affect perceptual experience, then that experience is eliminated (or at least weakened) as a possible source of evidence. Generally, desire-influenced perception will fail to provide a reason for belief.

\section{The case for orectic penetration}

It should be clear that the possibility of orectic penetration, and cognitive penetration more generally, is relevant to a number of issues in philosophy and cognitive science. Are there good reasons to think that orectic penetration actually occurs?

A number of psychologists have researched the effect that certain drives, in particular hunger, have on perceptual response. Seymour Epstein presented ambiguous stimuli to subjects who had been deprived of food for varying amounts of time (Epstein 1961). In brief, the experiments showed that food-related responses (the identification of people or animals seeking, preparing, or eating food in the ambiguous stimuli) varied directly with hunger, increasing through $8 \mathrm{~h}$ (but decreasing after $23 \mathrm{~h}$ ) of deprivation. ${ }^{12}$

This provides a potential example of orectic penetration. The subjects suffering from food-deprivation (and thus, crudely, having a desire for food) were more likely to see food-related items or activities in ambiguous figures. Put another way, they had experiences as of food items, and these experiences apparently depend in a nontrivial way on the hunger desires. As born out by the statistical evidence, without the

\footnotetext{
11 Siegel presents cognitive penetration as a potential general constraint on theories of epistemic justification. In particular, she argues that dogmatist theories of justification are ill-equipped to meet the constraints imposed by cognitive penetration (Siegel, forthcoming).

12 The conclusions presented here are experimentally sound, but there is some controversy surrounding a number of additional conclusions drawn by Epstein and others. For related studies and/or criticism, see Lazarus et al. (1953), Saugstad (1966, 1967) and Wolitzky (1967).
} 
hunger desire the subjects were much less likely to see food items. Hungry people, the thought would go, sometimes see what they want.

Here one might worry that while hunger is motivational, it lacks representational content and is better regarded as a primitive drive; hunger is non-cognitive. More recent work improves upon the older food-deprivation research. One set of research suggests that food-preferences-for instance, a preference for one beverage over another-biases the perceptual interpretation of ambiguous figures, where subjects disambiguate briefly displayed figures $(400 \mathrm{~ms})$ in a way that favours the desired outcome, namely, the preferred beverage (Balcetis and Dunning 2006). ${ }^{13}$ A second set of research suggests that objects that can fulfil immediate goals (a water bottle when thirsty; a $\$ 100$ bill) are seen as closer than they actually are, as contrasted with the perceived distance of less desirable objects (Balcetis and Dunning 2010). In both sets of studies, the influencing state is cognitive, at least insofar as it is representational and stands in appropriate relations with other cognitive states like belief and intention.

The cognitive impenetrability theorist might deny that the above data imply genuine cognitive penetration by appeal to one or more of some common sceptical strategies. The Epstein (1961) and Balcetis and Dunning (2006) data might be resisted by appeal to an attention-shift interpretation. This interpretation maintains that the prior cognitive state causes a change in the allocation of attention. Thus the link between cognition and perception is mediated by some act of attention. Pylyshyn's account, for example, rules out attention-shift cases as non-genuine cases of cognitive penetration since in such cases there is no internal, logical connection between the belief, goal, or other cognitive state and the computations performed by the perceptual system (Pylyshyn 1999, p. 343). Lacking this internal connection, there is nothing to properly call 'penetration'. ${ }^{14}$

The Balcetis and Dunning (2006) data might also be resisted by a memory interpretation. In these studies, subjects are tasked to categorize an ambiguous figure (e.g. a figure that is ambiguous between a seal or a horse) and told that they will be rewarded for certain categorization results (e.g. in one study, some subjects would receive a desirable food for reporting more sea creatures than farm animals, or vice versa). The results suggest to Balcetis and Dunning that desires are influencing how the ambiguous figures are perceived. But importantly, the categorization report is made after the figure has been displayed on a computer screen and then removed, and this leaves the door open for the alternative memory interpretation. Perhaps the

\footnotetext{
13 One worry regarding this particular study is that the reports of these subjects are not to be trusted (perhaps subjects report seeing the ambiguous figure in just the way that is supposed to result in the desirable beverage). Balcetis and Dunning respond to this worry with a follow up study that uses nonambiguous figures. In this set up, the subjects identify the non-ambiguous figures with $100 \%$ accuracy (no matter whether such identification results in the desirable or undesirable beverage). See Balcetis and Dunning (2006, p. 615).

14 Elsewhere, Pylyshyn suggests that the allocation of attention is one way that cognition can penetrate perception: it is one of two loci where "cognition intervenes in determining the nature of perception" (Pylyshyn 1999, p. 344). However, the cognitive influence takes place in a way that fails to meet Pylyshyn's internal, logical connection requirement (of genuine cognitive penetration). So it is unclear why such cases would be considered, by Pylyshyn or anyone else, cognitive penetration. See also Fodor (1988).
} 
subjects merely recall, and subsequently report, the stimulus to be a certain way, and as a result of some background desire (or expectation). This provides evidence for the uncontroversial phenomenon of cognition penetrating cognition, rather than for cognition penetrating experience.

Finally, a critic might resist these studies by another common strategy. Rather than evidencing some desire-influenced or otherwise cognitively affected perceptual experience, some of these data only suggest an influence on judgements or beliefs about the perceptual stimulus. According to this judgement interpretation, judgements are cognitively influenced in experimental subjects while experience remains unaffected across the subjects. For instance, one might resist the Balcetis and Dunning (2010) data by this method. In some of these studies, experimental subjects make distance estimates regarding a desired object. Subjects tend to underestimate the distance to a desired object, and so the experimenters suggest that desires are affecting visual experience. However, the data is open to the interpretation that subjects are simply misjudging the relevant distances as a result of the background desires. ${ }^{15}$

Grant that these interpretive strategies, if applicable, are effective; any putative case of cognitive penetration that can be interpreted along one of these three lines is not a genuine instance of cognitive penetration. Here a value of the definition articulated above, OP, becomes clear. Clause (1) of OP rules out both the memory and judgement interpretations, since it requires that a perceptual experience is cognitively influenced. Clause (2) rules out the attention-shift interpretation since it requires an internal link between the influencing desire and experience. The question then becomes whether any experimental cases satisfy OP.

Set to one side whether some of the above studies can be finessed to evidence perceptual experiences that meet OP and evade the three sceptical strategies. Instead, consider some research from the New Look psychology movement of the mid-twentieth century. As it turns out, one of the earliest New Look studies best evades the sceptical strategies. ${ }^{16}$

In a now well-known experiment, Jerome Bruner and C.C. Goodman found a number of interesting results regarding perceptual experiences of objects of social value (Bruner and Goodman 1947). In brief, the experiment ran as follows. Three groups (10 persons per group) of 10 year old children, two experimental and one control, were put before a wooden box with a glass screen on its face. In the centre of the screen was a small patch of light, nearly circular in shape, the diameter of which could be adjusted by a small knob located on the bottom right corner of the box. The two experimental groups of children were presented with ordinary coins of varying values. As they looked at the coins, placed flat in the palm of the left hand,

\footnotetext{
15 Balcetis and Dunning (2010) attempt to control for this possible scenario by introducing an actionbased report into later experiments. Here subjects toss an item as a distance estimate (rather than verbally providing a numerical estimate). For this to evade the relevant judgement interpretation, however, one has to make the contentious assumption that visual perception is directly linked with action and in these very kinds of perceptual circumstances.

16 Macpherson analyzes both the judgement and attention-shift strategies, arguing that both fail to handle data from colour perception studies performed by Delk and Fillenbaum (1965) (see Macpherson, forthcoming).
} 
positioned at the same height and six inches to the left of the adjustable patch of light, they were asked to adjust the patch to match the size of the presented coin. The subjects could take as much time as they liked to complete the task. The control group was instead presented with cardboard discs of sizes identical to the relevant coins, and asked to perform the same task. Here is the first result of interest: in the experimental group, perceptual experience of the coins was "accentuated." The experimental subjects systematically overestimated the size of the coin, and sometimes by a difference as high as $30 \%$ as compared with control subjects. (For instance, experimental subjects overestimated the size of a dime by an average of $29 \%$; controls underestimated the size of the cardboard analogue of a dime by $-1 \%$.)

The second experimental variation divided experimental groups into subgroups comprising "rich" children and "poor" children. The task was the same, except only real coins were used. Here the results are even more striking. Rich children, as the previous results would predict, still overestimate the size of the coins, but at percentages significantly lower than the poor children. Indeed, poor children systematically overestimate the size of coins, by as much as $50 \%$, and by differences as high as $30 \%$ as compared to rich children.

The general New Look hypothesis was that the value or subjective importance of the perceived object somehow works into the visual perception of the size of that object. This hypothesis is born out by both the first and second set of results mentioned above. Generally, children of such an age understand the social value of money, thus having some minimal desire for money, and as a result see the coins as bigger. And, Bruner and Goodman postulated, the poor children feel a greater need or desire for money and so perceive the coins as (even) bigger than they actually are.

A few historical notes are worth brief mention. The New Look psychological movement has proved to be controversial as a general theory of perception and cognition, with decades of research following Bruner and Goodman's (1947) study. Much of this research successfully produced relevantly similar results (e.g. Bruner and Postman 1948; Dukes and Bevan 1952; Bruner and Rodrigues 1953; Blum 1957; Holzkamp and Perlwitz 1966). Other research was critical: some researchers identified stimuli of value that did not influence perceptual reports in the same way (Lysak and Gilchrist 1955; Carter and Schooler 1949); others suggested that additional non-evaluative variables may be at work (Klein et al. 1951); others argued that the accentuation of perception by higher-level "affective" states was context-sensitive: occurring in some contexts but not others (Carter and Schooler 1949; Tajfel and Wilkes 1963). One should distinguish criticism that denies the weak claim that perception is sometimes directly affected by higher level mental states, from criticism to the effect that the details or scope of the New Look hypotheses require revision. The vast majority of criticism, including those listed above, falls into the second category. ${ }^{17}$ The use of the New Look studies here only requires the weaker claim, and this claim will be defended below against some standard critical strategies.

\footnotetext{
${ }^{17}$ See Jenkin (1957) and Tajfel (1957) for important theoretical reviews that support this general conclusion.
} 
If we take the reports of Bruner and Goodman's subjects as accurate with respect to what they see, then we have instances of orectic penetration as defined. The subject has a desire for money. This desire causally influences the subject's perceptual experience of coins, namely, it influences the size properties of the objects as experienced. And this influence is achieved internally: the background desires/s influence the visual processing of the coins. This interpretation has, nonetheless, been resisted. Critics appeal to one or more of the above strategiesthe memory, attention-shift, and judgement interpretations - to reject results like Bruner and Goodman (1947) as evidence for genuine cases of cognitive penetration. These methods for resistance as applied to this data, however, are less plausible than the interpretation they oppose.

The memory ${ }^{18}$ and attention-shift ${ }^{19}$ interpretations both fail for the same reason: they fail to apply given the experimental methods of Bruner and Goodman's studies. The subjects in this experiment had as much time as they liked to inspect the stimulus (coins for the experimental subjects) and adjust the patch of light while they inspected the stimulus. Moreover, the stimulus was located at the same horizontal level and six inches to the left of the adjustable light patch. Thus in no sense were the subjects making reports just based on memory; the memory interpretation fails. And in no relevant sense were the subjects inspecting the coin and then shifting attention to a distinct visual field. Of course there may be some gaze shifting between stimulus and adjustable light patch, but this would not have differed between control and experimental subjects and so would fail to explain the relevant differences between such subjects. The attention-shift interpretation fails.

Finally, a critic may appeal to the judgement interpretation. Here one responds to the Bruner and Goodman results by suggesting that the child's desire for money affects her beliefs or judgements about money. And children with less money, it turns out, make even grosser overestimates of the size of money. This judgement is then reported by the subjects and explains the differences recorded in the experimental results. Importantly, the only version of this interpretation that is inconsistent with the cognitive penetration of perception is one where the perceptual experiences of the subjects are static across control and experimental subjects alike. That is, like controls, the experimental subjects have an accurate perceptual experience of the coins; only their judgements are biased by their background desires. Pylyshyn flags this as a second scenario where cognition can influence perception. But as he describes it, here cognition influences "decisions involved in recognizing and identifying patterns" (Pylyshyn 1999, p. 344; emphasis added). This fails to meet any of the definitions of orectic penetration or, broadly, cognitive penetration (including Pylyshyn's own, as cited above). So this interpretation, as a final method of resisting genuine cognitive penetrability, is worth extended consideration.

One can begin to see the problems with application of the judgement interpretation by recalling the experimental setup in the Bruner and Goodman study. Again, subjects took as much time as they needed to adjust the light patch to

\footnotetext{
${ }^{18}$ McCurdy (1956).

${ }^{19}$ Fodor (1988) and Pylyshyn (1999).
} 
match the size of the coins that they currently inspected (the coins located six inches to the left of the patch). So the subjects were not making flash judgements. Instead, they were able to make well-considered adjustments, comparing the two visual stimuli at the same time in the same visual field. The judgement interpretation maintains that the (experimental) subject perceives the coin accurately. Simultaneously, the subject makes and eventually reports a judgement that mischaracterizes the size of the coin. Therefore, implausibly, this interpretation requires attributing a judgement or belief to the subject which does not correspond to the perceptual experience that she is having simultaneously with that judgement or belief.

In response, the cognitive impenetrability theorist may invoke clear examples where judgements or beliefs clearly come apart from simultaneous experience. To take one of the favoured examples, in spite of one's beliefs that the two lines in the Müller-Lyer illusion are of the same length, one will continue to see the lines as differing in length. One cannot, as it were, get one's beliefs to penetrate experience. $^{20}$ This is true for the Müller-Lyer and other similar illusions; but these illusions are not sufficiently analogous to the Bruner and Goodman experiments. The relevant difference is this: When a person reports (correctly) that the two Müller-Lyer lines are of the same length, she is not (and recognizes that she is not) basing the reported judgement on her perceptual experience (of the illusion as it is normally presented). She is instead relying on knowledge or testimony to judge and report that the lines are of the same length. By contrast, in performing the task given, Bruner and Goodman's subjects are inspecting the coin and ostensibly basing their report on what they see. They would certainly report that they are matching the light patch to what they are seeing. So, unlike persons perceiving the Müller-Lyer lines, these subjects intend for their action to report what they are seeing. To treat these subjects as analogous to perceivers of standard visual illusions would imply that the subjects are systematically mistaken about what they are doing: they are not reporting what they are seeing.

So the judgement interpretation does not readily apply to the Bruner and Goodman results. It requires that the subjects are not correctly reporting what they see, since their perceptual experience is accurate and the reported judgement inaccurate. Instead, this interpretation must maintain that these subjects are continually ignoring, remaining unconscious of, or somehow otherwise failing to accurately report a current perceptual experience. This is less plausible than the interpretation it opposes, namely, that experience is penetrated by desire.

One might finally respond by appealing to the fact that the subjects in Bruner and Goodman's study are children; perhaps this explains the relevant results. Note first that this explanation cannot be one premised on an immature failure to understand the experimental task: Bruner and Goodman take relevant precautions to insure that the young subjects understand what they are supposed to do, and how to manipulate the experimental apparatus (Bruner and Goodman 1947, p. 37). Nor will it suffice to appeal to the fact that poor children are less familiar with money (McCurdy 1956). This response fails to explain the first set of data, where children of varying economic backgrounds overestimate the size of coins relative to the controls who

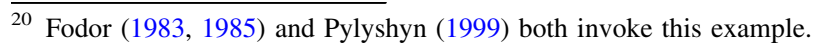


are presented with cardboard discs. And it commits to an implausible general hypothesis about perception. Children encounter unfamiliar stimuli all the time. There is no reason to think that, as a general fact about perception, a child's estimation of an object's size co-varies inversely with the familiarity of that object. Instead, to deflect the Bruner and Goodman results on the basis of the age of the experimental subjects, one would seem to have to make either of the following claims. Coins (and not cardboard discs) somehow affect the perceptual and cognitive capacities of children (and not adults) in such a way that either (a) children make inaccurate judgements about accurate perceptual experiences or (b) perceptual experiences of children are penetrated by background cognitive states regarding money. (a) refines the judgement interpretation as a description of only certain child perceivers in the relevant circumstances; (b) accepts cognitive penetrability, but just for kids.

Ultimately, the evidence is insufficient to conclusively rule out the first of these alternatives, (a). But here again, the evidence favours an inference to an interpretation that accepts cognitive penetration. In this context, the choice is between a consistent failure among children to make accurate judgements about certain classes of simultaneously perceived stimuli and not others versus a direct cognitive influence on perceptual experience. This is an easy choice. There is little reason to think that, relative to adult perceivers, the minds of children work as deviantly as the first choice requires. Rather, the best explanation is that the children are seeing the coins differently and making reports accordingly.

The Bruner and Goodman study itself leaves open the possibility that cognitive penetration is an effect found only in perceivers of younger ages (as per (b) above). An outstanding empirical question would then be whether these kinds of effects disappear as children mature. In fact, recent studies suggest otherwise. In one study, very much inspired by the New Look paradigm, adult perceivers estimate identically sized discs in a way that substantially varies depending upon whether the discs contain negative images versus neutral or positive images. The researchers conclude that the subjects have and apply background values to the varying images, and this influences size perception of the discs (van Ulzen et al. 2008). This provides good evidence that the general hypothesized phenomenon is not exclusive to children.

To conclude, the best explanation of the Bruner and Goodman (1947) data, given the experimental circumstances, is that perceptual experience is accurately reported by the subject's actions, namely, by her adjustment of the light patch. The subject sees the coin as bigger (than it actually is) and so reports that the coin is bigger. This experience causally depends, in a non-externally mediated way, upon the desires of the subject. And whether there is a judgement or belief that mediates the perceptual experience and the report is of no matter to the hypothesis. Either way, it is an instance of orectic penetration as defined. This is an important defence for any friend of a cognitive penetrability thesis, since it blocks the common strategies for deflecting putative cases of cognitive penetration. With respect to Bruner and Goodman's (1947) results_-as well as a number of the other New Look-inspired data cited above-the memory, attention-shift, and judgement interpretations are all less plausible than the cognitive penetration interpretation. Unless there is some 
fourth line of interpretation, these cases remain plausible cases of cognitive penetration generally and of orectic penetration specifically. The cognitive impenetrability theorist must find another strategy to dismiss them.

\section{Conclusion}

Desire-influenced perception would have significant practical and theoretical consequences. The possibility has typically been resisted, and by the same strategies used to resist the more general phenomenon of cognitive penetrability. Optimistically, the above discussion shows why these sceptical strategies fail to rule out the phenomenon as defined by OP and, more importantly, fail to deflect some of the adduced cases that meet OP. Granting this conclusion, the sceptic must devise a new strategy for resisting these and other putative cases of cognitive penetrability. More conservatively, the above discussion at least shows that there are more precise ways to conceptualize one type of cognitive penetrability: orectic penetration understood in terms of OP. And instances of this phenomenon are not so easily dismissed by the standard sceptical strategies. Ironically, it is a renewed look at the original New look studies that may provide the most compelling evidence, and hopefully revitalize philosophical discussion of and scientific experimentation on an interesting potential feature of the human mind.

Acknowledgments For discussion and feedback, thanks to Paul Bartha, Vince Di Lollo, Catherine Wilson. Special thanks to Vince Bergeron, Fiona Macpherson, Mohan Matthen, and Susanna Siegel for reading (multiple) drafts, and for invaluable conversation on this and related topics. Special thanks also to one anonymous reviewer (for this journal) for exceptionally helpful criticism.

\section{References}

Armstrong, D. (1980). The nature of the mind. St. Lucia, QLD: University of Queensland Press.

Balcetis, E., \& Dunning, D. (2006). See what you want to see: Motivational influences on visual perception. Journal of Personality and Social Psychology, 91(4), 612-625.

Balcetis, E., \& Dunning, D. (2010). Wishful seeing: Desired objects are seen as closer. Psychological Science, 21, 147-152.

Blum, A. (1957). The value factor in children's size perception. Child Development, 28, 14-18.

Brewer, W. F., \& Lambert, B. L. (2001). The theory-ladenness of observation and the theory-ladenness of the rest of the scientific process. Philosophy of Science, 68, 176-186.

Bruner, J. S., \& Goodman, C. C. (1947). Value and need as organizing factors in perception. Journal of Abnormal and Social Psychology, 42, 33-44.

Bruner, J. S., \& Postman, L. (1948). Symbolic value as an organizing factor in perception. Journal of Social Psychology, 27, 203-208.

Bruner, J. S., \& Rodrigues, J. S. (1953). Some determinants of apparent size. Journal of Abnormal and Social Psychology, 48, 17-24.

Carter, L. F., \& Schooler, K. (1949). Value need and other factors in perception. Psychological Review, 56, 200-207.

Churchland, P. M. (1979). Scientific realism and the plasticity of mind. Cambridge: Cambridge University Press.

Churchland, P. M. (1988). Perceptual plasticity and theoretical neutrality: A reply to Jerry Fodor. Philosophy of Science, 55, 167-187. 
Churchland, P. M. (1989). A neurocomputational perspective: The nature of mind and the structure of science. Cambridge, MA: MIT Press.

Delk, J. L., \& Fillenbaum, S. (1965). Differences in perceived colour as a function of characteristic color. The American Journal of Psychology, 78, 290-293.

Dukes, W. F., \& Bevan, W. (1952). Size estimation and monetary value: A correlation. Journal of Psychology, 34, 43-53.

Epstein, S. (1961). Food-related responses to ambiguous stimuli as a function of hunger and ego strength. Journal of Consulting Psychology, 25, 463-469.

Feyerabend, P. (1962). Explanation, reduction and empiricism. In H. Feigl \& G. Maxwell (Eds.), Minnesota studies in philosophy of science (Vol. 3, pp. 28-97). Minneapolis, MN: University of Minnesota Press.

Fodor, J. (1983). Modularity of mind. Cambridge, MA: MIT Press.

Fodor, J. (1984). Observation reconsidered. Philosophy of Science, 51, 23-43.

Fodor, J. (1985). Précis of the modularity of mind. The Behavioral and Brain Sciences, 8, 1-5.

Fodor, J. (1988). A reply to Churchland's 'Perceptual plasticity and theoretical neutrality'. Philosophy of Science, 55, 19-188.

Hanson, N. R. (1958). Patterns of discovery. Cambridge: Cambridge University Press.

Hanson, N. R. (1969). Perception and discovery: An introduction to scientific inquiry. San Francisco, CA: Freeman and Cooper.

Holzkamp, K., \& Perlwitz, E. (1966). Absolute oder relative Größenakzentuierung? Eine experimentelle Studie zur sozialen Wahrnehmung. Zeitschrift für Experimentelle und Angewandte Psychologie, 13, 390-405.

Jenkin, N. (1957). Affective processes in perception. Psychological Bulletin, 54, 100-127.

Klein, G. S., Schlesinger, H. J., \& Meister, D. E. (1951). The effect of personal values on perception-An experimental critique. Psychological Review, 58, 96-112.

Kuhn, T. (1962). The structure of scientific revolutions. Chicago, IL: University of Chicago Press.

Lazarus, R. S., Yosem, H., \& Arenberg, A. (1953). Hunger and perception. Journal of Personality, 21, 312-328.

Lysak, W., \& Gilchrist, J. C. (1955). Value, equivocality, and goal availability as determinants of size judgments. Journal of Personality, 23, 500-501.

Macpherson, F. (forthcoming). Cognitive penetration of colour experience: Rethinking the issue in light of an indirect mechanism. Philosophy and Phenomenological Research.

McCurdy, H. G. (1956). Coin perception studies and the concept of schemata. Psychological Review, 63, $160-168$.

Nagel, T. (1974). What is it like to be a bat? Philosophical Review, 83, 435-450.

Pylyshyn, Z. (1984). Computation and cognition. Cambridge, MA: MIT Press.

Pylyshyn, Z. (1999). Is vision continuous with cognition? The case for cognitive impenetrability of visual perception. Behavioral and Brain Sciences, 22(3), 341-365.

Saugstad, P. (1966). Effect of food deprivation on perception-cognition. Psychological Bulletin, 65, 80-90.

Saugstad, P. (1967). Comments on the article by David L. Wolitzky. Psychological Bulletin, 68, 345-346.

Schroeder, T. (2004). Three faces of desire. Oxford: Oxford University Press.

Siegel, S. (forthcoming). Cognitive penetrability and perceptual justification. Nous.

Smith, M. (1994). The moral problem. Cambridge, MA: Blackwell.

Sperber, D. (1996). Explaining culture: A naturalistic approach. Oxford: Blackwell.

Stalnaker, R. (1984). Inquiry. Cambridge, MA: MIT Press.

Stokes, D., \& Bergeron, V. (unpublished manuscript). A dilemma for modular architectures of the mind. Tajfel, H. (1957). Value and the perceptual judgment of magnitude. Psychological Review, 64, 192-204.

Tajfel, H., \& Wilkes, A. L. (1963). Classification and quantitative judgment. British Journal of Psychology, 54, 101-114.

van Ulzen, N. R., Semin, G. R., Oudejans, R., \& Beek, P. (2008). Affective stimulus properties influence size perception and the Ebbinghaus illusion. Psychological Research, 72, 304-310.

Wolitzky, D. L. (1967). Effect of food deprivation on perception-cognition: A comment. Psychological Bulletin, 68, 342-344. 